•研究报告・

\title{
新疆伊犁马铃薯根际芽胞杆菌纯培养多样性
}

\author{
刘国红 $\quad$ 刘 $\quad$ 波 $^{1^{*}} \quad$ 车建美 ${ }^{1} \quad$ 陈倩倩1 林乃铨 $^{2} \quad$ 崔卫东 $^{3}$ \\ 1 (福建省农业科学院农业生物资源研究所, 福州 350003) \\ 2 (福建农林大学植物保护学院, 福州 350002) \\ 3 (新疆农业科学院微生物应用研究所，乌鲁木齐 830000)
}

\begin{abstract}
摘要: 了解马铃薯根际土壤中芽胞杆菌种类多样性，可为挖掘芽胞杆菌新资源提供基础。从新疆伊犁州 9 个地点采 集了30份马铃薯根际土壤样品, 采用可培养法从中分离芽胞杆菌, 通过16S rRNA基因同源性鉴定了分离菌株的分 类地位。共获得芽胞杆菌349株, 基于菌落形态特征和16S rRNA基因序列确定了 66 个代表菌株, 其中 14 株与近缘种 模式菌株的 $16 \mathrm{~S}$ rRNA基因序列相似性介于93.0-98.5\%之间，为潜在芽胞杆菌新种。349株芽胞杆菌属于9属66种, 分别为芽胞杆菌属(Bacillus)的 41 个种 $(41 / 66,62.1 \%)$, 为最优势属; 类芽胞杆菌属(Paenibacillus) 有 9 种 $(9 / 66$, 13.6\%), 赖氨酸芽胞杆菌属(Lysinibacillus)共6种(6/66, 9.1\%), 嗜冷芽胞杆菌属(Pscychrobacillus)共4种(4/66, 6.1\%), 虚构芽胞杆菌属(Fictibacillus)有2种(2/66,3.0\%), 短芽胞杆菌属(Brevibacillus)、大洋芽胞杆菌属(Oceanobacillus)、 鲁梅尔芽胞杆菌属(Rummelibacillus)和解硫胺素芽胞杆菌属(Aneurinibacillus)皆为 1 种。新疆9个地点马铃薯根际土 壤中芽胞杆菌含量为 $2.20-8.86 \times 10^{4} \mathrm{cfu} / \mathrm{g}$, 其中特克斯蒙古乡马铃薯根际土壤中芽胞杆菌的菌落含量和种类最多, 分别为 $8.86 \times 10^{4} \mathrm{cfu} / \mathrm{g}$ 和 37 种; 尼勒克县马场马铃薯根际土壤中的芽胞杆菌含量最少, 特克斯去昭苏路上和阜康 西沟村的芽胞杆菌种类最少, 仅9种。但每个地点的优势种均相同, 均为简单芽胞杆菌(Bacillus simplex)和阿氏芽胞 杆菌(B. aryabhattai)。芽胞杆菌种类可划分为高频度分布型(简单芽胞杆菌等4种)、中频度分布型(植物内生芽胞杆 菌等12种)和低频度分布型(其余51种芽胞杆菌, 如菒状芽胞杆菌)。新疆9个地点芽胞杆菌种类分布可分为高含量高 丰度型(特克斯蒙古乡和农技推广园)和低含量低丰度型(如尼勒克县马场等地)。相关性分析发现, 马铃薯根际芽胞 杆菌种类分布与海拔高度无显著相关性。新疆马铃薯根际土壤蕴含种类丰富的芽胞杆菌资源, 可为芽胞杆菌功能 菌株开发提供丰富的菌种来源。
\end{abstract}

关键词：芽胞杆菌，马铃薯根际土壤，多样性

\section{Diversity of Bacillus-like species isolated from potato rhizosphere soils in Yili, Xinjiang}

\author{
Guohong Liu ${ }^{1}$, Bo Liu ${ }^{1 *}$, Jianmei Che ${ }^{1}$, Qianqian Chen ${ }^{1}$, Naiquan Lin $^{2}$, Weidong Cui ${ }^{3}$ \\ 1 Agricultural Bio-Resource Institute, Fujian Academy of Agricultural Sciences, Fuzhou 350003 \\ 2 College of Plant Protection, Fujian Agriculture and Forestry University, Fuzhou 350002 \\ 3 Institute of Applied for Microorganism of Xinjiang Academy of Agricultural Sciences, Urumqi 830000
}

\begin{abstract}
This study aims to understand the diversity of Bacillus-like species found in potato rhizosphere soils in Xinjiang, and provide a basis for mining new resources. Bacillus-like bacteria were isolated from potato rhizosphere soils using the cultivable method and preliminarily identified based on the 16S rRNA gene sequences. The spatial distribution pattern of the Bacillus-like bacteria was analyzed using frequency distribution and number. A total of 349 Bacillus-like isolates were obtained from 30 soil samples, and identified as 66 species belonging to 9 genera and 2 families (Bacillaceae and Paenibacillaceae) within Bacilli by $16 \mathrm{~S}$ rRNA gene sequences. Sixty six selective strains were chosen to be further analyzed based on colony morphology and 16S rRNA gene sequences, and 14 strains were potential novel species based on the lower
\end{abstract}

收稿日期: 2017-03-08; 接受日期: 2017-06-06

基金项目：国家自然科学基金(31370059)、福建省自然科学基金(2016J01129)、福建省公益项目(2015R1018-7)、福建省农科院 PI 项目(2016PI-43)和院 青年英才计划(YJRC2015-17)。

* 通讯作者 Author for correspondence. E-mail: fzliubo@163.com 
similarities found between $93.0-98.5 \%$ in their closed references type strains. The species numbers of each genus were 41 for Bacillus (41/66, 62.1\%), 9 for Paenibacillus (9/66, 13.6\%), 6 for Lysinibacillus (6/66, 9.1\%), 4 for Pscychrobacillus (4/66, 6.1\%), 2 for Fictibacillus (2/66, 3.0\%), and 1 for Brevibacillus, Oceanibacillus, Rummelibacillus and Aneurinibacillus, respectively. In the potato rhizosphere soils, the content range of Bacillus-like species were $2.20-8.86 \times 10^{4} \mathrm{cfu} / \mathrm{g}$. The highest colony content and Bacillus-like species, e.g. $8.86 \times 10^{4} \mathrm{cfu} / \mathrm{g}$ and 37 species, respectively, occurred in the Mongolian township of Tekes, while the lowest colony content was found in a stud-farm in Nilka County and the lowest Bacillus-like species (9 species) were found in Xigou Village of Fukang City and on the way from Tekes to Zhaosu County. There was large difference in the distribution of Bacillus-like species in the potato rhizosphere soils, but each site was characterized by the same dominant species, Bacillus simplex and Bacillus aryabhattai. Based on their occurrence frequency, the Bacillus-like species could be discriminated as high frequency species including Bacillus simplex, middle frequency species including Bacillus endophyticus, and low frequency species including Bacillus mycoides. Based on the number of Bacillus-like species, 9 collecting sites were divided into two groups, namely high content and richness and low content and richness. Moreover, there was no significant correlation between the distribution of Bacillus-like species and altitude. Thus, there were many Bacillus-like species in potato rhizosphere soils, which provide rich resources for exploring functional strains.

Key words: Bacillus species; potato rhizosphere soil; diversity

马铃薯是世界上很多国家非常重要的食品, 目 前有130个国家将其作为重要的非谷物食品(Calvo et al, 2010; 徐海泉等, 2015)。芽胞杆菌是一类重要 的微生物资源, 在自然界中广泛分布(Liu et al, 2016), 其大多数种类能够产生多种功能代谢产物, 有些种类能防治马铃薯软腐病(Rahman et al, 2012) 和青枯病(Calvo et al, 2010; Saber et al, 2015), 有些 种类对马铃薯生长具有促生作用(Calvo et al, 2010; Hanif et al, 2015)。目前，尽管已有300多种芽胞杆菌 被分离鉴定(LPSN), 但仍有大量的芽胞杆菌资源及 其活性物质有待挖掘。土壤是芽胞杆菌及其生物活 性物质的一个重要来源, 植物根际土壤的芽胞杆菌 能够保护植物根部不被病原菌侵染, 且其中一些种 类还对植物具有促生长能力 (Asari et al, 2016; Huang et al, 2015; Liu et al, 2016a)。植物根际微生 物组研究变得越来越重要, 健康的微生物组能促 进植物的生长, 而植物根际土壤中的芽胞杆菌是 健康微生物组的重要成员之一。

新疆是我国马铃薯主要种植基地之一, 昌吉回 族自治州和哈萨克自治州(简称伊犁州)种植了大量 的马铃薯。秦越等(2015)利用末端限制性片段长度 多态性(T-RFLP)技术分析了连作栽培对马铃薯根际 微生物多样性的影响, 发现芽胞杆菌是根际微生物 的优势属, 占比例最大。王娜等(2016)也通过 T-RFLP分析发现间作后马铃薯根际土壤细菌数量 增加, 多样性指数高于连作栽培, 而且间作栽培能
够有效改善马铃薯根际土壤细菌菌群结构, 使一些 有益菌属比例上升, 潜在致病菌比例下降甚至消失, 且出现了新的益生菌。白洋(2014) ${ }^{\oplus}$ 采用T-RFLP技术 探究了用稻草包芯栽培方式在马铃薯不同生长时 期土壤细菌种类的变化, 表明整个生育时期稻草包 芯处理后土壤细菌种类波动较小, 根际细菌中病菌 数量较少, 益生菌(如芽胞杆菌等)的比例较大, 有 益芽胞杆菌主要是侧胞短芽胞杆菌 (Brevibacillus laterosporus)、短短芽胞杆菌(Brevibacillus brevis)、 短小芽胞杆菌(Bacillus pumilus)等。

我们从新疆 9 个地点采集了马铃薯种根际土壤 样本, 采用可培养法从中分离芽胞杆菌, 通过 $16 \mathrm{~S}$ rRNA基因系统发育分析芽胞杆菌的分类地位, 以 期为进一步挖掘利用马铃薯根际土壤中芽胞杆菌 资源提供参考。

\section{1 材料与方法}

\section{1 土壤样品采集}

2013年7月27-30日, 于新疆伊犁州9个地点采 集了马铃薯根际土壤样品30份(表1), 保存于无菌自 封袋, 室温保存带回实验室放于 $4{ }^{\circ} \mathrm{C}$ 冰箱保存, 进 行芽胞杆菌分离。

\section{2 培养基和试剂}

PCR 仪和凝胶成像分析仪购自Bio-Rad公司;

(1) 白洋 (2014) 马铃薯稻草包芯栽培的土壤酶活与细菌种 群变化研究. 硕士学位论文, 福建农林大学, 福州. 
表 1 新疆马铃薯根际土壤样本采集信息

Table 1 Information of potato rhizosphere soil samples from Xinjiang

\begin{tabular}{llll}
\hline 编号 No. & 采集地点 Collection site & 海拔 Altitude (m) & 经纬度 Location \\
\hline S1 & 尼勒克县尼勒克镇公社种子队 Seed Team of Nilka Township, Nilka County & 1,138 & $43^{\circ} 46^{\prime} 28^{\prime \prime} \mathrm{N}, 82^{\circ} 35^{\prime} 01^{\prime \prime} \mathrm{E}$ \\
S2 & 阜康市上户沟乡西沟村 Xigou Village, Shanghugou Township, Fukang City & 1,261 & $44^{\circ} 00^{\prime} 17^{\prime \prime} \mathrm{N}, 88^{\circ} 33^{\prime} 46^{\prime \prime} \mathrm{E}$ \\
S3 & 尼勒克县马场 Machang, Nilka County & 1,139 & $43^{\circ} 45^{\prime} 58^{\prime \prime} \mathrm{N}, 82^{\circ} 34^{\prime} 43^{\prime \prime} \mathrm{E}$ \\
S4 & 尼勒克县沙勒漫乡 Shaleman Township, Nilka County & 1,110 & $43^{\circ} 47^{\prime} 08^{\prime \prime} \mathrm{N}, 82^{\circ} 32^{\prime} 15^{\prime \prime} \mathrm{E}$ \\
S5 & 昭苏县农业局试验场 Testing Ground of Agricultural Bureau, Zhaosu County & 1,856 & $44^{\circ} 09^{\prime} 46^{\prime \prime} \mathrm{N}, 81^{\circ} 09^{\prime} 14^{\prime \prime} \mathrm{E}$ \\
S6 & 特克斯蒙古乡(施药) Mongolia Township, Tekes County (pesticide applied) & 1,171 & $43^{\circ} 13^{\prime} 25^{\prime \prime} \mathrm{N}, 81^{\circ} 54^{\prime} 27^{\prime \prime} \mathrm{E}$ \\
S7 & 特克斯蒙古乡 Mongolia Township, Tekes County & 1,181 & $43^{\circ} 13^{\prime} 17^{\prime \prime} \mathrm{N}, 81^{\circ} 52^{\prime} 33^{\prime \prime} \mathrm{E}$ \\
S8 & 特克斯去昭苏路上 On the way from Tekes to Zhaosu County & - \\
S9 & 特克斯县农业技术推广园 Agro Technical Extension Garden, Tekes County & 1,181 & $43^{\circ} 13^{\prime} 17^{\prime \prime} \mathrm{N}, 81^{\circ} 52^{\prime} 33^{\prime \prime} \mathrm{E}$ \\
\hline
\end{tabular}

恒温培养箱(BI-250AG)购自施都凯仪器设备(上海) 有限公司; $2 \times \mathrm{PCR}$ Master Mix购自上海铂尚生物技 术有限公司; 引物由上海铂尚生物技术有限公司合 成。LB培养基配制参考葛慈斌等(2015)的描述。

\section{3 芽胞杆菌的分离与鉴定}

土壤中芽胞杆菌的分离主要参考刘国红等 (2014)的方法。称取土壤样品 $10 \mathrm{~g}$ 至 $90 \mathrm{~mL}$ 无菌水, 震荡混匀 $20 \mathrm{~min}$ 后, $80^{\circ} \mathrm{C}$ 水浴 $10 \mathrm{~min}$, 土壤悬浮液依 次稀释成浓度为 $10^{-1} 、 10^{-2} 、 10^{-3}$ 。取 $100 \mu \mathrm{L}$ 悬浮液 至 $\mathrm{LB}$ 平板并涂布均匀, $30^{\circ} \mathrm{C}$ 培养 2 天后观察菌落生 长情况。根据菌落形态特征等进行芽胞杆菌种类归 类、统计计数及纯化, 采用 $-80^{\circ} \mathrm{C}$ 甘油冷冻法进行保 存。采用Tris-饱和酚法提取芽胞杆菌基因组DNA, 参考Cheng和Jiang (2006) 描述的方法。采用通用细 菌16S rRNA引物进行扩增、测序, 主要参考Liu等 (2016b)描述的方法。16S rRNA基因扩增引物为 $27 \mathrm{~F}$ (5'-AGAGTTTGATCCTGGCTCAG-3') 和 1492R(5'GGTTACCT TGTTACGACTT- $3^{\prime}$ )。检测出有条带的 菌株PCR产物送至上海铂尚生物技术有限公司进行 测序。

\section{4 芽胞杆菌的系统发育分析}

根据所得到序列在网站 (http://www.ezbiocloud.net/)上进行序列比对分析后(Kim et al, 2012), 结合BLASTn和RDP数据库比对初步判断得出芽胞 杆菌种的分类地位。选择相关的参考菌株序列, 再 经Clustal X对齐后(Thompson et al, 1997), 用软件 Mega 6.0采用邻接法和Jukes-Cantor模型构建系统 发育树(Jukes \& Cantor, 1969; Felsenstein et al, 1985; Saitou \& Nei, 1987; Tamura et al, 2013)。

\section{5 芽胞杆菌种类多样性分析}

统计各采样点马铃薯根际土样本芽胞杆菌种 类数、数量总和, 比较各样本芽胞杆菌种类的变化, 分析芽胞杆菌种类在各个采样点土壤样本中出现 的频次和数量。

\section{6 芽胞杆菌种群数量、分离频度、海拔间的相关 性分析}

对 9 个地点的芽胞杆菌, 用DPS统计软件进行 在土壤中的数量与海拔之间, 以及分离频度与在土 壤中的数量之间的相关性分析。

\section{2 结果}

\section{1 芽胞杆菌的分离与鉴定}

根据分离菌株的菌落形态特征进行归类统计, 共分离获得芽胞杆菌349株, 通过对菌株16S rRNA 基因序列的同源性进行比对，对349个菌株进行 16S rRNA基因序列分析并最终确定66个代表菌株进行 后续分析。

基于 $16 \mathrm{~S}$ rRNA基因系统发育分析结果表明, 在细菌属水平上的种群多样性非常丰富, 349株菌 隶属9个属的66个种。芽胞杆菌属(Bacillus) 41 个种 (41/66, 62.1\%), 类芽胞杆菌属(Paenibacillus) 9 个种 (9/66, 13.6\%), 赖氨酸芽胞杆菌属(Lysinibacillus) 6 个种 $(6 / 66,9.1 \%)$, 嗜冷芽胞杆菌属 (Pscychrobacillus) 4 个种 $(4 / 66,6.1 \%)$, 虚构芽胞杆菌属(Fictibacillus) 2 个种 $(2 / 66,3.0 \%)$, 短芽胞杆菌属(Brevibacillus)、大洋芽胞杆菌属(Oceanobacillus)、鲁梅 尔芽胞杆菌属(Rummelibacillus)和解硫胺素芽胞杆 菌属(Aneurinibacillus) 皆为 1 个种。 $16 \mathrm{~S}$ rRNA相似性 
在93-100\%之间，说明部分分离菌株与其亲缘关系 最近的模式种之间可能存在一定的遗传差异。

\section{2 芽胞杆菌资源系统发育分析}

66种芽胞杆菌的 $16 \mathrm{~S}$ rRNA基因序列系统发育 分析见图1。其中, FJAT-21955、FJAT-21963、FJAT21352、FJAT-18003、FJAT-21351和FJAT-18019与其 最相近模式菌株的 $16 \mathrm{~S}$ rRNA基因相似性皆低于 $97.0 \%$, 分别为 $93.5 \%$ (Bacillus altitudinis $41 \mathrm{KF}^{2} \mathrm{~b}^{\mathrm{T}}$ )、 94.1\% (Pscychrobacillus psychrodurans DSM $11713^{\mathrm{T}}$ )、 94.3\% (Bacillus simplex NBRC $5720^{\mathrm{T}}$ )、96.5\% (Baciillus drentensis LMG 21831 ${ }^{\mathrm{T}}$ )、96.9\% (Bacillus paraflexus $\mathrm{RC} 2^{\mathrm{T}}$ )和 $97.0 \%$ (Paenibacillus uliginis N3/ 975 ${ }^{\mathrm{T}}$ 。 FJAT-18017、FJAT-22090和FJAT- 18069与其 亲缘关系最近模式菌株的 $16 \mathrm{~S}$ rRNA基因相似性位 于97-98\%之间, 分别为 $97.4 \%$ (Bacillius thioparans BMP-1 ${ }^{\mathrm{T}}$ )、97.7\% (Pscychrobacillus psychrodurans DSM $11713^{\mathrm{T}}$ ) 和 $97.8 \%$ (Lysinibacillus macroides LMG 18474 ${ }^{\mathrm{T}}$ )。FJAT-22048、FJAT-22140、FJAT22098、FJAT-22121和FJAT-18000与其最近模式菌株 的相似性介于 $98-98.5 \%$ 之间, 分别为 $98.2 \%$ (Bacillus horneckiae DSM 23495 ${ }^{\mathrm{T}}$ )、98.3\% (Bacillus decolorationis LMG $19507^{\mathrm{T}}$ )、98.3\% (Lysinibacillus varians $\mathrm{GY}_{32}{ }^{\mathrm{T}}$ )、 $98.4 \%$ (Bacillus fortis) 和 $98.4 \%$ (Psychrobacillus insolitus DSM 5 ${ }^{\mathrm{T}}$ )。根据原核生物种 的界定阈值标准, 上述菌株可能为芽胞杆菌潜在新 种, 为最终确定其分类地位, 我们正在用包括生理 生化特征、MLST序列分析、DNA-DNA杂交以及脂 肪酸分析等多相分类方法对其进行鉴定, 以确定其 准确的分类地位。

\section{3 芽胞杆菌种类分布频次}

马铃薯根际芽胞杆菌种类分布可分为三大类: 高频度分布型、中频度分布型和低频度分布型。

高频度分布类型包含 4 个种即简单芽胞杆菌 (Bacillus simplex)、阿氏芽胞杆菌(B. aryabhattai)、 矮缩芽胞杆菌 (B. atrophaeus) 和短小芽胞杆菌 (B. pumilus)。其中简单芽胞杆菌和阿氏芽胞杆菌存在 于 9 个采集地点的所有土壤样本中, 矮缩芽胞杆菌 在除特克斯去昭苏路上之外的其他 8 个地点的样本 中获得 $(8 / 9,88.9 \%)$, 短小芽胞杆菌在除尼勒克县尼 勒克镇公社种子队一队和尼勒克县沙勒漫乡外的7 个地点获得 $(7 / 9,77.8 \%)$ 。

中频度类型分布在 4-6个地点的土壤样本中，
包含 12 种芽胞杆菌, 分别为植物内生芽胞杆菌 (Bacillus endophyticus)、耐寒芽胞杆菌(B. frigoritolerans)、地衣芽胞杆菌(B. licheniformis)、烟酸芽胞 杆菌(B. niacini)、嗜气芽胞杆菌(B. aerophilus)、苏 云金芽胞杆菌(B. thuringiensis)、图瓦永芽胞杆菌(B. toyonensis)、含低嗍赖氨酸芽胞杆菌(Lysinibacillus parviboronicapiens)、忍冷嗜冷芽胞杆菌( P. psychrodurans)、蜡状芽胞杆菌(B. cereus)、病研所芽胞 杆菌(B. idriensis)和沙福芽胞杆菌(B. safensis)。其中 沙福芽胞杆菌分布在尼勒克县尼勒克镇公社种子 队一队、尼勒克县马场、尼勒克县沙勒漫乡、昭苏 县农业局试验场、特克斯蒙古乡和特克斯农业科技 推广园6个地点。

低频度类型分布在少数几个地点, 分布极不均 一。分布在1-3个地点的土壤样品中, 包含其余的 51 种芽胞杆菌，其中 14 种为潜在芽胞杆菌新种。

\section{4 芽胞杆菌种类及数量多样性}

芽胞杆菌种类含量分布结果见表2。9个地点马 铃薯根际土壤中芽胞杆菌含量不同, 菌落含量范围 为 $2.20-8.86 \times 10^{4} \mathrm{cfu} / \mathrm{g}$, 尼勒克县马场土壤样品中 的芽胞杆菌含量最少 $\left(2.20 \times 10^{4} \mathrm{cfu} / \mathrm{g}\right)$, 特克斯蒙古 乡芽胞杆菌的含量最多 $\left(8.86 \times 10^{4} \mathrm{cfu} / \mathrm{g}\right)$ 。

马铃薯根际土芽胞杆菌优势菌群都是简单芽 胞杆菌, 每个地点分离到的芽胞杆菌种类不一致: 特克斯蒙古乡马铃薯根际土中分离到的芽胞杆菌 种类最多, 为 37 种; 其次是特克斯农技推广园(31 种), 最少的为特克斯 $\rightarrow$ 昭苏和阜康西沟村, 皆为 9 种。

\begin{tabular}{|c|c|c|}
\hline $\begin{array}{l}\text { 样本编号 } \\
\text { Sample no. }\end{array}$ & $\begin{array}{l}\text { 芽胞杆菌含量 } \\
\text { Bacillus colonies content }\left(\times 10^{4}\right. \\
\text { cfu/g) }\end{array}$ & $\begin{array}{l}\text { 种类数 } \\
\text { Species number }\end{array}$ \\
\hline S1 & 3.25 & 19 \\
\hline S2 & 5.00 & 9 \\
\hline S3 & 2.20 & 11 \\
\hline S4 & 6.60 & 15 \\
\hline S5 & 3.97 & 15 \\
\hline S6 & 7.70 & 15 \\
\hline S7 & 8.86 & 37 \\
\hline S8 & 4.30 & 9 \\
\hline S9 & 3.76 & 31 \\
\hline
\end{tabular}




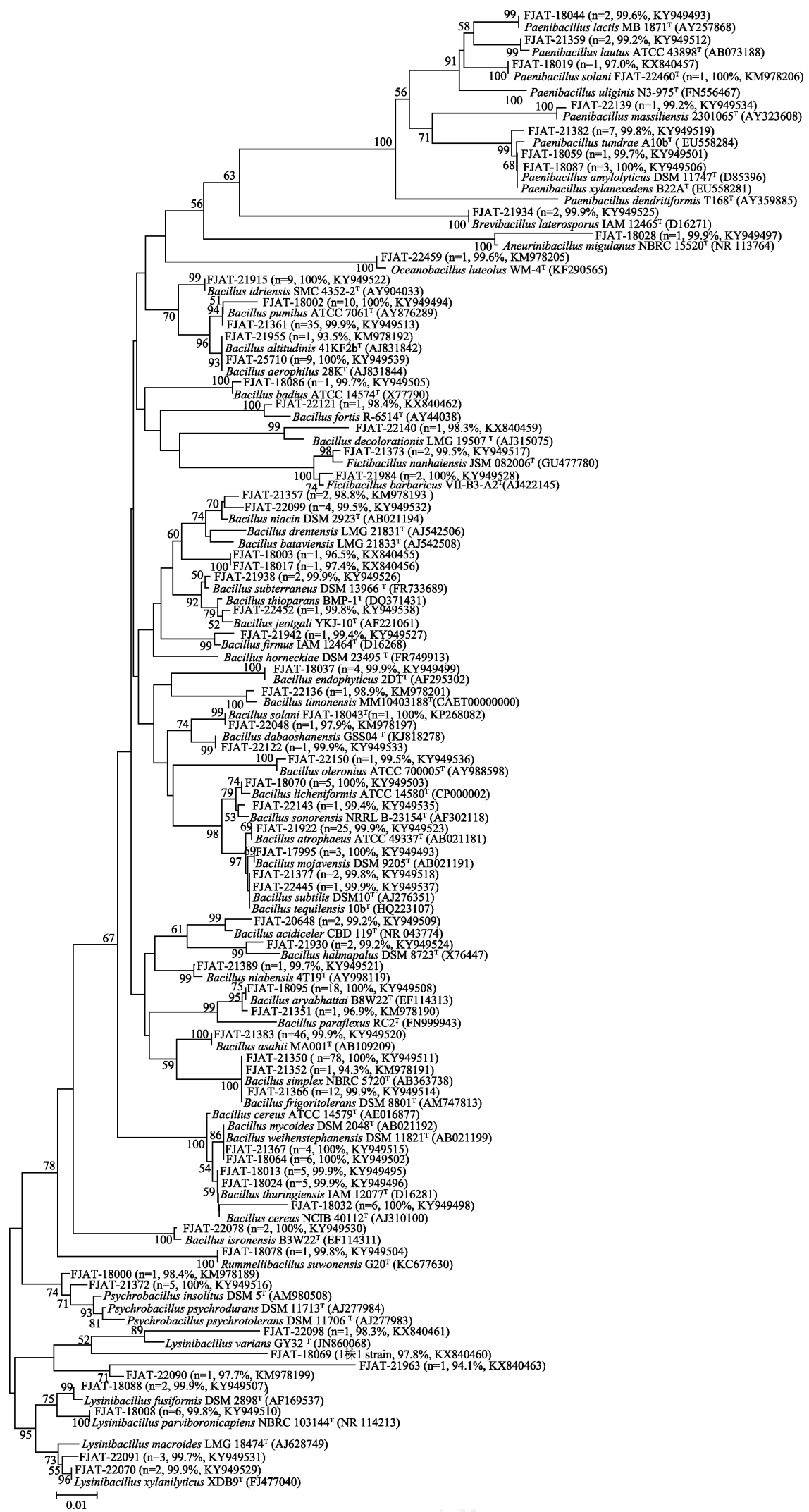

图 1 基于 16S rRNA 基因的芽胞杆菌系统发育分析。 $\mathrm{n}$ 代表分离菌株数量，百分比值为分离菌株与近缘模式菌的 16S rRNA 基因相似性。

Fig. 1 Phylogenetic analysis of Bacillus species based on 16S rRNA gene sequence. $\mathrm{n}$ represents number of isolates, and percent values represent the 16S rRNA gene sequence similarities between isolates and related type species. 


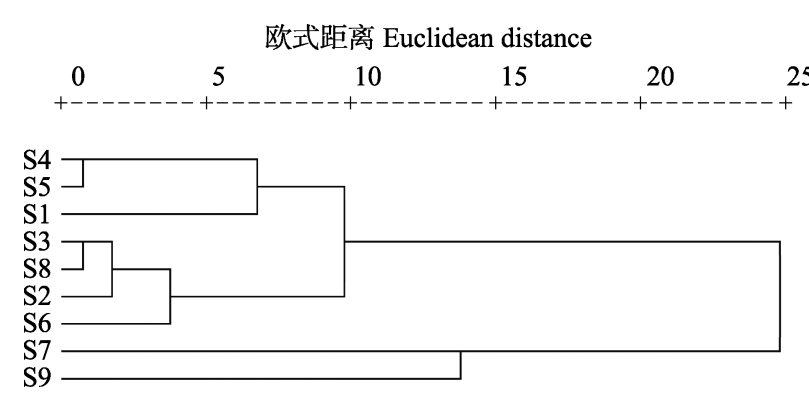

图 2 马铃薯根际土壤样品采集点的聚类分析。编号 S1-9 同表 1.

Fig. 2 Analysis of collection sites of potato rhizosphere soils. Soil samples S1-9 are the same as Table 1.

\section{5 芽胞杆菌含量聚类分析}

以表 2 数据构建矩阵进行聚类分析(图 2 ), 当 $\lambda=$ 15 时, 9 个采集地点的芽胞杆菌种类分布可划分为 3 大类: 第I类为高含量高丰度型, 包含特克斯蒙古乡 和农技推广园; 第II类为低含量低丰度型, 包含其 余7个土壤样本采集点, 可分为两大亚类型, 分别 为低含量中丰度型和中含量低丰度型。

\section{3 讨论}

本研究结合纯培养法和16S rRNA基因系统发 育分析法, 对新疆伊犁马铃薯根际土壤中芽胞杆菌 种类多样性进行了调查。研究结果表明, 马铃薯根 际土壤中可培养的芽胞杆菌种群多样性非常丰富, 获得的349株芽胞杆菌隶属于芽胞杆菌目9个属的 66 个种。其中多数菌株属于芽胞杆菌属, 该属的简 单芽胞杆菌和阿氏芽胞杆菌几乎分布在所有采集 的土壤样本中。马铃薯根际土壤存在一定量的芽胞 杆菌潜在新资源, 目前已正式发表了 2 个新种, 即 茄科芽胞杆菌(Bacillus solani FJAT-18043 ${ }^{\mathrm{T}}$ ) (Liu et al，2015)和茄科类芽胞杆菌 (Paenibacillus solani FJAT-22460 ${ }^{\mathrm{T}}$ ) (Liu et al, 2016b), 其余14株与其最相 近模式菌株的 $16 \mathrm{~S}$ rRNA 基因序列同源性在 93.0-98.5\%之间。这些潜在新种的分类地位和生物 学特性需进一步深入研究。

国内外学者基于 $16 \mathrm{~S}$ rRNA基因的系统发育法 分析了番茄(马宁宁, 2013)、烟草、玉米、田七、甘 蔗、小麦、毛竹等植物根际土壤中芽胞杆菌物种分 布。将本研究结果与上述结果进行比较, 发现本研 究获得的芽胞杆菌在上述植物根际土壤中均有分 布，皆为作物根际的优势属。马铃薯块茎表面含有
丰富的芽胞杆菌, 主要为短小芽胞杆菌(Weinert et al，2010), 且部分菌株具有一定的抗病原菌活性, 而本研究从马铃薯根际土壤中也获得了一定量的 短小芽胞杆菌资源, 可能具有作为马铃薯病原菌生 防制剂研发的潜力。毛竹根际土壤中含有大量的芽 胞杆菌属和类芽胞杆菌属菌群, 优势种是蜡状芽胞 杆菌和萆状芽胞杆菌, 这与本文调查分析结果不同, 而且毛竹根际获得的类芽胞杆菌种类在马铃薯根 际也不存在(李潞滨等, 2008), 这可能与植株本身的 特性相关。烟草根际和非根际土壤中均含有丰富的 芽胞杆菌资源，优势种为巨大芽胞杆菌，与同为茄 科作物的马铃薯根际的优势种不同 (林风敏等, 2011)。田七和马铃薯根际的阿氏芽胞杆菌均为优势 种，但田七的优势种苏云金芽胞杆菌和Bacillus siamensis (Fan et al, 2016)在马铃薯根际含量不多, 而本研究获得的优势种简单芽胞杆菌和萎缩芽胞 杆菌(B. atrophaeus)在田七根际含量也很少。同为粮 食作物的玉米根际土壤中的优势芽胞杆菌种类与 本文研究结果相同(刘国红等, 2014), 但含有的芽胞 杆菌种类远低于马铃薯根际, 这可能与采集样本的 数量和作物特性相关。Verma等(2016)在小麦根际获 得的优势种群为蜡状芽胞杆菌类群(Bacillus cereus group)、枯草芽胞杆菌类群(Bacillus subtilis group) 和巨大芽胞杆菌(Bacillus megaterium), 而纺锤形赖 氨酸芽胞杆菌 (Lysinibacillus fusiformis)和解木糖赖 氨酸芽胞杆菌(Lysinibacillus xylanilyticus)在马铃薯 根际均存在，为低频率分布型。芽胞杆菌属是甘蔗 根际土壤厚壁菌门的优势属(Pisa et al, 2011), 连作 花生田根际土壤的优势菌为简单芽胞杆菌和巨大 芽胞杆菌(颜艳伟等, 2011), 但本研究未分离获得巨 大芽胞杆菌。

Sikorski等(2008)调查发现以色列“进化谷”芽胞 杆菌种群结构丰富多样, 其中简单芽胞杆菌分布在 所有采集样本中, 本文研究发现马铃薯土壤样品中 亦含有高频率分布的简单芽胞杆菌, 这可能与该种 自身生物特性有一定的相关性。简单芽胞杆菌能产 生挥发性有机化合物, 提高马铃薯的产量(Velivelli et al, 2015), 还可以高效消除化学需氧量, 用于降 解土壤中的氯磺隆和除草剂氟乐灵(Erguven et al, 2016)。阿氏芽胞杆菌亦具有广泛的分布特性, Lee 等(2012)发现贫痊土壤含有丰富的阿氏芽胞杆菌且 对意大利苍耳(Xanthium italicum)具有促生作用，具 
有作为植物生长促生剂的潜力。藏红花(Crocus sativus)根际土壤和非根际土中均含有大量的阿氏 芽胞杆菌(Ambardar \& Vakhlu, 2013)。Zhang等(2013) 首次报道萎缩芽胞杆菌能产生3种抗真菌物质, 高 效抑制多种病原真菌生长，可用于植物病原菌防治， 笔者亦从马铃薯根际获得了高频率分布的萎缩芽 胞杆菌资源，该种群可能对马铃薯的病害防治具有 很大的作用。Verma等(2016)首次报道小麦根际土壤 中的植物内生芽胞杆菌 (B. endophyticus) 和食木糖 类类芽胞杆菌(Paenibacillus xylanexedens)具有多功 能的促生作用, 本文从马铃薯根际土壤中也获得了 中频率分布的植物内生芽胞杆菌和低频率分布的 食木糖类类芽胞杆菌, 这 2 种芽胞杆菌可能对马铃 薯生长具有一定的促进作用。

\section{参考文献}

Ambardar S, Vakhlu J (2013) Plant growth promoting bacteria from Crocus sativus rhizosphere. World Journal of Microbiology and Biotechnology, 29, 2271-2279.

Asari S, Matzén S, Petersen MA, Bejai S, Meijer J (2016) Multiple effects of Bacillus amyloliquefaciens volatile compounds: plant growth promotion and growth inhibition of phytopathogens. FEMS Microbiology Ecology, 92, pii: fiw070.

Cheng HR, Jiang N (2006) Extremely rapid extraction of DNA from bacteria and yeasts. Biotechnology Letters, 28, 55-59.

Calvo P, Ormeño-Orrillo E, Martínez-Romero E, Zúñiga D (2010) Characterization of Bacillus isolates of potato rhizosphere from andean soils of Peru and their potential PGPR characteristics. Brazilian Journal of Microbiology, 41, 899-906.

Erturk Y, Ercisli S, Haznedar A, Cakmakci R (2010) Effects of plant growth promoting rhizobacteria (PGPR) on rooting and root growth of kiwifruit (Actinidia deliciosa) stem cuttings. Biological Research, 43, 91-98.

Fan ZY, Miao CP, Qiao XG, Zheng YK, Chen HH, Chen YW, Xu LH, Zhao LX, Guan HL (2016) Diversity, distribution, and antagonistic activities of rhizobacteria of Panax notoginseng. Journal of Ginseng Research, 40, 97-104.

Felsenstein J (1985) Confidence limits on phylogenies: an approach using the bootstrap. Evolution, 39, 783-789.

Hanif MK, Hameed S, Imran A, Naqqash T, Shahid M, Van Elsas JD (2015) Isolation and characterization of a $\beta$-propeller gene containing phosphobacterium Bacillus subtilis strain KPS-11 for growth promotion of potato (Solanum tuberosum L.). Frontiers in Microbiology, 6, 583.

Huang XF, Zhou D, Guo J, Manter DK, Reardon KF, Vivanco JM (2015) Bacillus spp. from rainforest soil promote plant growth under limited nitrogen conditions. Journal of Applied Microbiology, 118, 672-684.

Ge CB, Liu B, Che JM, Chen MC, Liu GH, Wei JC (2015) Diversity of Bacillus species inhabiting on the surface and endophyte of lichens collected from Wuyi Mountain. Acta Microbiologica Sinica , 55, 551-563. (in Chinese) [葛慈斌, 刘波, 车建美, 陈梅春, 刘国红, 魏江春 (2015) 武夷山 地衣表生和内生芽胞杆菌种群的多样性. 微生物学报, 55, 551-563.]

Jukes TH, Cantor CR (1969) Evolution of protein molecules. In Mammalian Protein Metabolism, Vol. 3 (ed. Munro HN), pp. 21-132. Academic Press, New York.

Kim OS, Cho YJ, Lee K, Yoon SH, Kim M, Na H, Park SC, Jeon YS, Lee JH, Yi H, Won S, Chun J (2012) Introducing EzTaxon-e: a prokaryotic 16S rRNA gene sequence database with phylotypes that represent uncultured species. International Journal of Systematic and Evolutionary Microbiology, 62, 716-721.

Lee S, Ka JO, Song HG (2012) Growth promotion of Xanthium italicum by application of rhizobacterial isolates of Bacillus aryabhattai in microcosm soil. Journal of Microbiology, 50, 45-49.

Li LB, Liu M, Yang SZ, Liu L, Miao K, Yang K, Han JG (2008) Cultivable microbial diversity at the rhizosphere of Phyllostachys pubescens. Acta Microbiologica Sinica, 48, 772-779. (in Chinese with English abstract) [李潞滨, 刘敏, 杨淑贞, 刘亮, 缪芘, 杨凯, 韩继刚 (2008) 毛竹根际可 培养微生物种群多样性分析. 微生物学报, 48, 772-779.]

Lin FM, Ji WX, Li HL (2011) Phylogenetic diversity of culturable bacteria in rhizosphere and non-rhizosphere of tabacco. Hubei Agricultural Sciences, 50, 1058-1062. (in Chinese with English abstract) [林凤敏, 姬文秀, 李虎林 (2011) 烟草根际与非根际细菌的系统发育多样性研究. 湖北农业科学, 50, 1058-1062.]

Liu B, Liu GH, Cetin S, Schumann P, Pan ZZ, Chen QQ (2016a) Bacillus gobiensis sp. nov., isolated from a soil sample. International Journal of Systematic and Evolutionary Microbiology, 66, 379-384.

Liu B, Liu GH, Sengonca C, Schumann P, Ge CB, Wang JP, Cui WD, Lin NQ (2015) Bacillus solani sp. nov., isolated from rhizosphere soil of potato field in Xinjiang of China. International Journal of Systematic and Evolutionary Microbiology, 65, 4066-4071.

Liu B, Liu GH, Sengonca C, Schumann P, Lan JL, Chen DJ, Cui WD, Lin NQ (2016b) Paenibacillus solani sp. nov., isolated from potato rhizosphere soil in Xinjiang, China. International Journal of Systematic and Evolutionary Microbiology, 66, 4486-4491.

Liu GH, Zhu YJ, Liu B, Che JM, Tang JY, Pan ZZ, Chen ZH (2014) Diversity of culturable Bacillus species from maize (Zea mays) rhizosphere soil. Journal of Agricultural Biotechnology, 22, 1367-1379. (in Chinese with English abstract) [刘国红, 朱育菁, 刘波, 车建美, 唐建阳, 潘志针, 
陈泽辉 (2014) 玉米根际土壤芽胞杆菌的多样性. 农业 生物技术学报, 22, 1367-1379.]

Liu Y, Chen L, Zhang N, Li Z, Zhang G, Xu Y, Shen Q, Zhang $R$ (2016) Plant-microbe communication enhances auxin biosynthesis by a root-associated bacterium, Bacillus amyloliquefaciens SQR9. Molecular Plant-Microbe Interactions, 29, 324-330.

Ma NN (2013) Study on soil microbial of properties in protected tomato root cirumference. PhD dissertation, Shenyang Agricultural University, Shenyang. (in Chinese with English abstract) [马宁宁 (2013) 设施番茄根围土壤的微生物特 性研究. 博士学位论文, 沈阳农业大学, 沈阳.]

Pisa G, Magnani GS, Weber H, Souza EM, Faoro H, Monteiro RA, Daros E, Baura V, Bespalhok JP, Pedrosa FO, Cruz LM (2011) Diversity of 16S rRNA genes from bacteria of sugarcane rhizosphere soil. Brazilian Journal of Medical and Biological Research, 44, 1215-1221.

Qin Y, Ma K, Liu P (2015) Effect of potato continuous cropping on genetic diversity of soil microorganisms. Chinese Journal of Eco-Agriculture, 23, 589-596. (in Chinese with English abstract) [秦越, 马琨, 刘萍 (2015) 马铃薯连作 栽培对土壤微生物多样性的影响. 中国生态农业学报, 23, 589-596.]

Rahman MM, Ali ME, Khan AA, Akanda AM, Uddin MK, Hashim U, Hamid SBA (2012) Isolation, characterization, and identification of biological control agent for potato soft rot in Bangladesh. Scientific World Journal, 2012, 723293.

Saber WI, Ghoneem KM, Al-Askar AA, Rashad YM, Ali AA, Rashad EM (2015) Chitinase production by Bacillus subtilis ATCC 11774 and its effect on biocontrol of rhizoctonia diseases of potato. Acta Biologica Hungarica, 66, 436-448.

Saitou N, Nei M (1987) The neighbor-joining method: a new method for reconstructing phylogenetic trees. Molecular Biology and Evolution, 4, 406-425.

Sikorski J, Brambilla E, Kroppenstedt RM, Tindall BJ (2008) The temperature-adaptive fatty acid content in Bacillus simplex strains from 'Evolution Canyon', Israel. Microbiology, 154, 2416-2426.

Tamura K, Stecher G, Peterson D, Filipski A, Kumar S (2013) MEGA 6: molecular evolutionary genetics analysis 6.0. Molecular Biology and Evolution, 30, 2725-2729.

Thompson JD, Gibson TJ, Plewniak F, Jeanmougin F, Higgins DG (1997) The CLUSTAL_X windows interface: flexible strategies for multiple sequence alignment aided by quality analysis tools. Nucleic Acids Research, 25, 4876-4882.

Velivelli SL, Kromann P, Lojan P, Rojas M, Franco J, Suarez JP, Prestwich BD (2015) Identification of mVOCs from Andean rhizobacteria and field evaluation of bacterial and mycorrhizal inoculants on growth of potato in its center of origin. Microbial Ecology, 69, 652-667.

Verma P, Yadav AN, Khannam KS, Kumar S, Saxena AK, Suman A (2016) Molecular diversity and multifarious plant growth promoting attributes of Bacilli associated with wheat (Triticum aestivum L.) rhizosphere from six diverse agroecological zones of India. Journal of Basic Microbiology, $56,44-58$.

Wang N, Lu SS, Ma K, Liu P (2016) The genetic diversity of rhizosphere soil bacteria under different intercropping patterns for potato in southern mountainous area of Ningxia. Journal of Arid Land Resources and Environment, 30(12), 193-198. (in Chinese with English abstract) [王娜, 陆姗姗, 马琨, 刘萍 (2016) 宁夏南部山区马铃薯不同间作模式 对根际土壤细菌多样性的影响. 干旱区资源与环境, 30(12), 193-198.]

Weinert N, Meincke R, Gottwald C, Heuer H, Schloter M, Berg G, Smalla K (2010) Bacterial diversity on the surface of potato tubers in soil and the influence of the plant genotype. FEMS Microbiology Ecology, 74, 114-123.

Xu HQ, Wang XL, Ma GS (2015) Nutrition feasibility analysis of development of potato as a staple food. Food and Nutrition in China, 21(7), 10-13. (in Chinese with English abstract) [徐海泉, 王秀丽, 马冠生 (2015) 马铃薯及其主食 产品开发的营养可行性分析. 中国生物与营养, 21(7), 10-13.]

Yan YW, Zhang H, Liu L, Xian HQ, Cui DJ (2011) Isolation and identification of dominant microorganisms in rhizosphere of continuous cropping with peanut. Acta Microbiologica Sinica, 51, 835-842. (in Chinese with English abstract) [颜艳伟, 张红, 刘露, 咸洪泉, 崔德杰 (2011) 连 作花生田根际土壤优势微生物的分离和鉴定. 微生物学 报, 51, 835-842.]

Zhang X, Li B, Wang Y, Guo Q, Lu X, Li S, Ma P (2013) Lipopeptides, a novel protein, and volatile compounds contribute to the antifungal activity of the biocontrol agent $B a$ cillus atrophaeus CAB-1. Applied Microbiology and Biotechnology, 97, 9525-9534.

(责任编委: 东秀珠 责任编辑: 时意专) 